\title{
A comparison of the clinical duration and recovery characteristics of cisatracurium after priming using rocuronium or cisatracurium - preliminary study
}

\author{
Ki Tae Jung, Jae Wook Kim, Tong Kyu Kim, and Tae Hun An \\ Department of Anesthesiology and Pain Medicine, School of Medicine, Chosun University, Gwangju, Korea
}

Background: The priming technique can speed up the onset of cisatracurium during intubation. However, there have been no reports on the effect of the priming technique on duration or recovery profile of cisatracurium. Therefore, we attempted to determine whether or not a priming technique with rocuronium or cisatracurium can affect clinical duration or recovery profiles of cisatracurium.

Methods: A total of 36 patients, ASA I and II, who were scheduled to undergo elective surgery, were enrolled. The patients were randomized into three groups and administered different drugs for the priming technique. Patients in group 1 received normal saline (control group). Patients in group 2 received rocuronium $(0.06 \mathrm{mg} / \mathrm{kg}$ ), and those in group 3 received cisatracurium $(0.01 \mathrm{mg} / \mathrm{kg})$ as a priming agent. Three minutes after injection of drugs, intubation doses of cisatracurium were administered (Group 1, $0.15 \mathrm{mg} / \mathrm{kg}$; Groups 2 and 3, $0.14 \mathrm{mg} / \mathrm{kg}$ ). Anesthesia was induced and maintained with propofol and remifentanil. Onset time, clinical duration, recovery index, recovery time, and total recovery time were measured by train of four monitoring.

Results: Onset time in the group 2 was significantly shorter than that of group 1 or $3(\mathrm{P}<0.05)$. However, no significant differences in clinical duration, recovery index, recovery time, and total recovery time were observed among the three groups.

Conclusions: Priming with rocuronium for 3 minutes resulted in significantly accelerated onset of cisatracurium. However, it did not affect the clinical duration and recovery profiles of cisatracurium. (Korean J Anesthesiol 2014; 66: 18-22)

Key Words: Cisatracurium, Neuromuscular monitoring, Recovery of function, Rocuronium.

Received: April 30, 2013. Revised: May 30, 2013. Accepted: June 26, 2013.

Corresponding author: Tae Hun An, M.D., Ph.D., Department of Anesthesiology and Pain Medicine, School of Medicine, Chosun University Hospital, 365, Phimun-daero, Dong-gu, Gwangju 501-717, Korea. Tel: 82-62-220-3223, Fax: 82-62-223-2333, E-mail: than@chosun.ac.kr

(c) This is an open-access article distributed under the terms of the Creative Commons Attribution Non-Commercial License (http:// creativecommons.org/licenses/by-nc/3.0/), which permits unrestricted non-commercial use, distribution, and reproduction in any medium, provided the original work is properly cited. 


\section{Introduction}

The priming technique has been introduced in order to facilitate the onset of non-depolarizing neuromuscular blocking drug (NMBD) for rapid-sequence intubation (RSI). Nevertheless, the declining popularity of the priming technique is obvious because of the use of rocuronium [1,2] which can be used as an acceptable NMBD for RSI [3]. However, sometimes, in cases of hepatic or renal failure, it seems reasonable to choose cisatracurium as a NMBD $[1,4]$. Therefore, it has been researched numerous priming techniques to overcome long onset time of cisatracurium [1,4-6]. Such priming techniques can speed up the onset of cisatracurium during intubation, but there have been no reports on the effect of priming technique on duration and recovery profile of cisatracurium. Therefore, we investigated the question of whether or not priming with rocuronium or cisatracurium can affect clinical duration or recovery profiles of cisatracurium.

\section{Materials and Methods}

This randomized study was approved by the Institutional Review Board and 36 patients with American Society of Anesthesiologists (ASA) physical status I-II, aged 20-65 years, who were scheduled to undergo elective surgery, were enrolled finally (Fig. 1). Patients with an allergy to cisatracurium or rocuronium, known difficult airway (Mallampati class III or IV), fever, preg- nancy, high risk of aspiration, a body mass index $<19$ or $>28$, significant hepatic or renal disease, neuromuscular disease, or any premedication (anticonvulsants, aminoglycosides or polypeptide antibiotics) that might influence neuromuscular function were excluded from the study. Prior to conduct of the study, informed consent was obtained from each subject, which also included an explanation of the procedure. The study protocol referred to the guidelines on pharmacodynamic studies of NMBD [7].

All patients received midazolam ( $0.05 \mathrm{mg} / \mathrm{kg}$ intramuscularly) for relieving anxiety 30 minutes before induction of anesthesia. When the patient had arrived in the operating room, standard monitoring including an electrocardiogram, pulse oximetry, non-invasive arterial pressure, and the bispectral index (BIS monitor A-2000; Aspect Medical Systems, Norwood, MA, USA) were started. An NMT sensor (888418 M-NMT MechanoSensor, Datex-Ohmeda Inc., Helsinki, Finland) was attached between the thumb and index finger and two stimulating electrodes were placed over the ulnar nerve on the opposite site of the intravenous line.

The patients were randomized into three groups through a computerized randomization. Patients in group 1 received normal saline and constituted the control group. Those in group 2 and group 3 received rocuronium $0.06 \mathrm{mg} / \mathrm{kg}$ and cisatracurium $0.01 \mathrm{mg} / \mathrm{kg}$ as a priming agent, respectively.

After preoxygenation for three minutes with tidal volume,

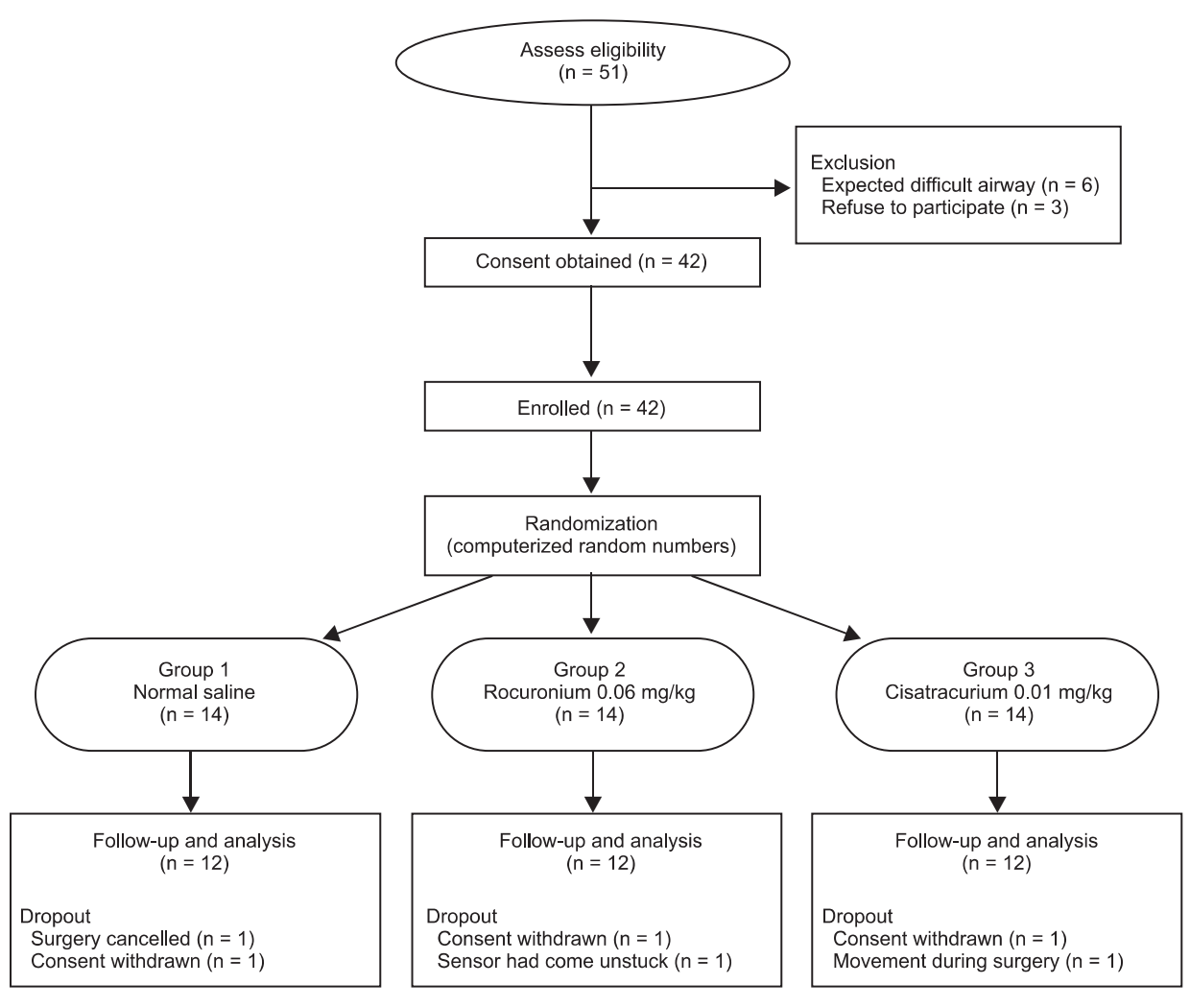

www.ekja.org
Fig. 1. Flow chart of patient enrollment. 
anesthesia was induced with propofol and remifentanil. A target controlled infusion device (Orchestra ${ }^{\circledR}$ Base Primea, FreseniusVial, France) using Marsh and Minto pharmacokinetic model was used. The targeted effect-site concentrations of propofol and remifentanil were $3 \mu \mathrm{g} / \mathrm{ml}$ and $2.5 \mathrm{ng} / \mathrm{ml}$, respectively. After induction, assisted ventilation with a mask was done with only $50 \%$ oxygen-air mixture for maintaining of normal endtidal carbon dioxide levels (30 to $40 \mathrm{mmHg}$ ). A propofol effectsite concentration of $3.0 \pm 2.0 \mu \mathrm{g} / \mathrm{ml}$ and a remifentanil effectsite concentration of $2.5 \pm 2.0 \mathrm{ng} / \mathrm{ml}$ were used. So, the changes of mean blood pressure and heart rate were maintained below $20 \%$ of variation and the bispectral index value was maintained between 40 and 60 . A nasopharyngeal temperature probe was inserted and a skin temperature probe was attached on the thena muscle for maintenance of normothermia and to reduce the influence of temperature on neuromuscular transmission.

Neuromuscular function was assessed with Train-of-four (TOF) stimuli after induction of anesthesia to prevent patient's discomfort. The TOF stimuli module performed an automatic searched for the optimal stimulus current for the maximal response of the adductor pollicis muscle and the corresponding electromyographic amplitudes were measured and displayed on an anesthetic monitoring system (Anesthetic Monitoring System $\mathrm{S} / 5^{\mathrm{TM}}$, Datex-Ohmeda Inc., Helsinki, Finland). At the beginning, stimulus was given at $10 \mathrm{~mA}$ for measuring initial response and the stimulus current was increased in steps of $5 \mathrm{~mA}$. Maximal current was detected when the response does not increase despite of the increase of current. And then, the supramaximal current was setted automatically at the current which is $115 \%$ of maximal current. If the response was too weak to find out supramaximal current, the electrode position was changed and the procedure repeated. If the repositioning of the electrodes does not work, the current was set at $70 \mathrm{~mA}$. Each patient's supramaximal stimulation was given every 0.5 second and repeated every 10 seconds.

After measurement of baseline value of TOF, patients received priming drug according to the randomization number, which was diluted into a volume of $1 \mathrm{ml}$ by an independent anesthetic nurse who did not participate in the anesthesia. After priming period ( 3 minutes), patients received intubation doses of cisatracurium (Group 1, $0.15 \mathrm{mg} / \mathrm{kg}$; Groups 2 and 3, $0.14 \mathrm{mg} / \mathrm{kg}$ ) which were also diluted to a volume of $10 \mathrm{ml}[1,6]$. After induction, no more NMBD was administered until the end of study.

The time from the end of cisatracurium injection to $95 \%$ depression of $\mathrm{T} 1$ response was measured as an onset time (OT). Clinical duration was defined as the time from the end of cisatracurium injection until T1 of the TOF had recovered to $25 \%$ of the control T1 value (CD). Recovery characteristics were measured as follows: (1) the time between 25 and $75 \%$ recovery of the control T1 value (recovery index, RI); (2) the time between $25 \%$ recovery of the control T1 value and a TOF ratio of 0.9 (recovery time, RT); (3) the time between administration of NMBD and a TOF ratio of 0.9 (total recovery time, TRT). OT was measured in seconds and the other values were measured in minutes [8].

Calculation of sample size was based on the average time of CD of the previous study [9]. The average time of clinical duration of cisatracurium after the using priming technique was 56.7 \pm 1.5 minutes and we assumed an increased time of $25 \%$ more than the average time of CD as a prolonged duration $(56.7 \times$ $1.25=70.875)$. We supposed that CD of group 2 might be the longest, and that $\mathrm{CD}$ of group 1 and 3 might be equal. With a 0.05 level of significance and $80 \%$ power, the required sample size was 11 patients in each group. We assumed a dropout rate of $20 \%$, so 14 patients were enrolled.

Data are expressed as mean \pm standard deviation (SD). ASA class and gender were compared among the three groups using Chi-Square test. Age, weight, height, body mass index, OT, CD, RI, RT, and TRT were analyzed by one-way ANOVA. P values < 0.05 were considered statistically significant. Data were analyzed using SPSS (Windows ver. 12.0, SPSS Inc., Chicago, IL).

\section{Results}

A total of 51 patients were recruited for the study and 36 patients were finally enrolled (Fig. 1). Demographic data of pa-

Table 1. Demographic Variables

\begin{tabular}{lcccc}
\hline & $\begin{array}{c}\text { Group 1 } \\
\text { (control; } \mathrm{n}=12)\end{array}$ & $\begin{array}{c}\text { Group 2 } \\
\text { (rocuronium; } \mathrm{n}=12)\end{array}$ & $\begin{array}{c}\text { Group 3 } \\
\text { (cisatracurium; } \mathrm{n}=12)\end{array}$ & P \\
\hline Age $(\mathrm{yr})$ & $49.67 \pm 8.57$ & $53.42 \pm 6.19$ & $48.83 \pm 11.13$ & 0.412 \\
Weight $(\mathrm{kg})$ & $65.00 \pm 13.59$ & $59.92 \pm 6.52$ & $63.17 \pm 8.47$ & 0.459 \\
Height $(\mathrm{cm})$ & $163.92 \pm 9.86$ & $158.92 \pm 5.00$ & $163.75 \pm 8.17$ & 0.230 \\
BMI $\left(\mathrm{kg} / \mathrm{m}^{2}\right)$ & $24.00 \pm 3.14$ & $23.76 \pm 2.72$ & $23.56 \pm 2.50$ & 0.927 \\
Gender $(\mathrm{M}: \mathrm{F})$ & $3: 9$ & $1: 11$ & $3: 9$ & 0.492 \\
ASA class $(1: 2)$ & $6: 6$ & $9: 3$ & $9: 3$ & 0.325 \\
\hline
\end{tabular}

Values are expressed as mean \pm SD or $\mathrm{n}$. BMI: body mass index. No significant differences in demographic variables were observed among the groups. ASA: American Society of Anesthesiologists. 
Table 2. Onset Time, Clinical Duration, Recovery Parameters

\begin{tabular}{lcccc}
\hline & $\begin{array}{c}\text { Group 1 } \\
\text { (control; } \mathrm{n}=12)\end{array}$ & $\begin{array}{c}\text { Group 2 } \\
\text { (rocuronium; } \mathrm{n}=12)\end{array}$ & Group 3 \\
(cisatracurium; $\mathrm{n}=12)$ & P \\
\hline OT (sec) & $121.6 \pm 27.8$ & $60.1 \pm 11.6^{*}$ & $110.8 \pm 45.6$ & 0.000 \\
CD (min) & $57.3 \pm 6.9$ & $55.7 \pm 10.0$ & $55.8 \pm 8.8$ & $16.8 \pm 6.2$ \\
RI (min) & $12.2 \pm 5.4$ & $13.6 \pm 8.1$ & $34.4 \pm 8.8$ & 0.882 \\
RT (min) & $33.1 \pm 5.7$ & $31.7 \pm 4.4$ & $89.3 \pm 11.0$ & 0.593 \\
TRT (min) & $90.3 \pm 11.1$ & $87.3 \pm 13.2$ & 0.819 \\
\hline
\end{tabular}

Data are presented as mean \pm standard deviation. OT: onset time, CD: clinical duration, RI: recovery index, RT: recovery time, TRT: total recovery time. *The mean difference is significant at the .05 level when multiple comparisons of onset time between groups were performed using GamesHowell post hoc tests. No significant differences in clinical duration, recovery index, and recovery time were observed among the groups.

tients were comparable among the three groups and showed no significant differences (Table 1).

Significant differences in onset time were observed among the three groups $(\mathrm{P}<0.05)$. Onset time fulfilled normality but not homogeneity of variances, thus, the Welch test with GamesHowell for post hoc test was used instead of one-way ANOVA (Table 2). Onset time in group 2 was $60.1 \pm 11.6$ seconds which was significantly shorter compared with the other group (121.8 \pm 27.8 seconds in group $1,110.8 \pm 45.6$ seconds in group 3 ).

Clinical duration was $57.3 \pm 6.9,55.7 \pm 10.0$, and $55.8 \pm 8.8$ minutes in group 1, group 2, and group 3, respectively. Recovery index in the current study was $12.2 \pm 5.4,13.6 \pm 8.0$, and $16.8 \pm$ 6.2 minutes in the group 1, group 2, and group 3, respectively. As analyzed by one-way ANOVA, clinical duration, recovery index, recovery time, and total recovery time were not significantly different among the three groups (Table. 2).

\section{Discussion}

Results of this study revealed that priming with rocuronium or cisatracurium does not result in significantly prolonged clinical duration or recovery characteristics. In particular, using a priming technique with rocuronium could hasten the onset time of cisatracurium without concern of prolonged block.

Cisatracurium is a non-depolarizing neuromuscular blocker with potency approximately four times higher than that of atracurium, has no histamine release, and has a very stable cardiovascular effect even at a dose eight times as high as $95 \%$ effective dose [10]. In addition, its unique metabolism, organ-independent Hoffmann elimination, makes cisatracurium attractive in patients with decreased hepatic or renal function $[1,4,10]$.

Therefore, a large number of studies have been conducted for establishment of proper methods for reduction of onset time of action with cisatracurium $[1,4,8]$. In addition, rocuronium has been used as a priming drug and the onset time of cisatracurium has shown a significant reduction $[1,6]$.

However, combination of NMBDs with different structures (benzylisoquinoliniums and aminosteroids) may produce syn- ergic effects, and synergism has been found for pairs of cisatracurium and vecuronium or rocuronium [11,12]. The previous studies focused only on the onset time of action. However no investigation of duration of action or recovery profiles when rocuronium was administered as a priming drug followed by administration of cisatracurium has been reported. Therefore, the authors have conducted the current study.

As mentioned previously, combination with NMBDs which have different molecular structure can be more synergic than that with similar molecular structure $[11,12]$. In particular, the synergism may be maximized if two molecules have different roles in prejunctional effect and postjunctional effect, respectively [11]. England et al. [13] suggested that rocuronium has higher affinity for presynaptic sites than the other NMBDs, which leads to the high mean recovery time/onset time ratio of 31 (other NMBDs had a ratio between 6 and 12), which means that rocuronium has a relatively long duration of action compared to short onset time, atypically. Thus, we hypothesized that clinical duration will be prolonged in group 2 because of high affinity for the prejunctional nicotinic-acetylcholine receptor of rocuronium and recovery characteristics would also be affected by rocuronium. Actually, the mean recovery time/onset time ratios of the current study was approximately 16.3, 31.6, and 18.6 in group 1, group 2, and group 3, respectively. However, high recovery time/onset time ratio of group 2 was on account of shortening of onset time only; no significant differences in clinical duration and recovery time were observed among the groups.

We proposed some hypothetical reasons for the similar results in clinical duration and recovery characteristics among the groups. First, no differences were observed in postjunctional effects of cisatracurium and rocuronium. Therefore, synergism would not be great enough to prolong the clinical duration, although rocuronium has a greater prejunctional effect. Lin et al. [6] has also reported on a study of T1/T0\% of TOF and TOF fade (T4/T1\%) after priming with rocuronium or cisatracurium and administration of cisatracurium, which reflect the postjunctional and prejunctional effects of the neuromuscular junction. According to the result, priming with rocuronium showed more 
prejunctional effect than did cisatracurium, however, postjunctional effects of both drugs were equal. Second, the dose of priming solution was so small and just enough to affect onset of action. Breslin et al. [14] has conducted research on pharmacodynamic interactions between cisatracurium and rocuronium. They administered rocuronium $0.6 \mathrm{mg} / \mathrm{kg}$ followed by cisatracurium $0.03 \mathrm{mg} / \mathrm{kg}$ when the first twitch in the TOF had recovered to $25 \%$, and found that clinical duration of maintenance doses of cisatracurium was prolonged by $33 \%$. The dose of rocuronium used in our study was just the priming dose $(0.06 \mathrm{mg} / \mathrm{kg})$; thus, the effect of rocuronium would have waned into insignificance at the point of recovery. In addition, priming doses are so small that the interaction between drugs may become less significant [14]. Finally, it is difficult to determine an exact explanation because of the obscurity of mechanism of the synergistic interactions between different groups of NMBDs, multiple receptor sites of NMBDs in the neuromuscular junction [15], altered protein binding and tissue binding by either drugs [14], or etc.

Sexual imbalance of the subjects was the limitation of the present study. There were much more females than males in the subjects. We selected thyroidectomy for the study in order to secure minimal movement of arm and because of relative long operation time enough to measure total recovery time. Thus, sexual imbalance was inevitable because of difference of prevalence rate.

In conclusion, even though priming with rocuronium can result in significantly accelerate onset of cisatracurium. It does not affect the clinical duration and recovery profiles of cisatracurium, thus there would be no need for concern with regard to synergic effect or prolonged duration of action when rocuronium is used as a priming agent for cisatracurium.

In addition, further evaluation about the effects of reversal agents on clinical duration and recovery profiles after using priming technique is needed, because reversal agents are used in the majority of cases in clinical setting.

\section{Acknowledgments}

This study was supported by research fund from Chosun University, 2011.

\section{References}

1. Mak PH, Irwin MG. The effect of cisatracurium and rocuronium on cisatracurium precurarization and the priming principle. J Clin Anesth 2004; $16: 83-7$.

2. El-Orbany M, Connolly LA. Rapid sequence induction and intubation: current controversy. Anesth Analg 2010; 110: 1318-25.

3. Perry JJ, Lee JS, Sillberg VA,Wells GA. Rocuronium versus succinylcholine for rapid sequence induction intubation. Cochrane Database Syst Rev 2008; CD002788.

4. Ahn BR, Kim SH, Yu BS, Lim KJ, Sun JJ. The effect of low dose ketamine and priming of cisatracurium on the intubating condition and onset time of cisatracurium. Korean J Anesthesiol 2012; 63: 308-13.

5. Ghodraty MR, Saif AA, Kholdebarin AR, Rokhtabnak F, Pournajafian AR, Nikzad-Jamnani AR, et al. The effects of magnesium sulfate on neuromuscular blockade by cisatracurium during induction of anesthesia. J Anesth 2012; 26: 858-63.

6. Lin SP, Chang KY, Chen YJ, Lin SM, Chang WK, Chan KH, et al. Priming with rocuronium to accelerate the onset time of cisatracurium during intubation. J Chin Med Assoc 2009; 72: 15-9.

7. Fuchs-Buder T, Claudius C, Skovgaard LT, Eriksson LI, Mirakhur RK, Viby-Mogensen J. Good clinical research practice in pharmacodynamic studies of neuromuscular blocking agents II: the Stockholm revision. Acta Anaesthesiol Scand 2007; 51: 789-808.

8. Kim SH, So KY, Jung KT. Effect of magnesium sulfate pretreatment on onset and recovery characteristics of cisatracurium. Korean J Anesthesiol 2012; 62: 518-23.

9. Deepika K, Kenaan CA, Bikhazi GB, Martineau DB. Influence of the priming technique on pharmacodynamics and intubating conditions of cisatracurium. J Clin Anesth 1999; 11: 572-5.

10. Naguib M, Lien CA. Pharmacology of muscle relexants and their antagonists. In: Miller's anesthesia. 7th ed. Edited by Miller R: Philladelphia, Churchill Livingston. 2010, pp 859-911.

11. Kim KS, Chun YS, Chon SU, Suh JK. Neuromuscular interaction between cisatracurium and mivacurium, atracurium, vecuronium or rocuronium administered in combination. Anaesthesia 1998; 53: 872-8.

12. Liu M, Dilger JP. Synergy between pairs of competitive antagonists at adult human muscle acetylcholine receptors. Anesth Analg 2008; 107: 525-33.

13. England AJ, Panikkar K, Redai I, Haxby E, Gopinath S, Feldman SA. Is rocuronium an exception to the relation between onset and offset? A comparison with pipecuronium. Eur J Anaesthesiol 1996; 13: 385-8.

14. Breslin DS, Jiao K, Habib AS, Schultz J, Gan TJ. Pharmacodynamic interactions between cisatracurium and rocuronium. Anesth Analg 2004; 98: 107-10.

15. Van der Spek AF, Zupan JT, Pollard BJ, Schork MA. Interactions of vecuronium and atracurium in an in vitro nerve-muscle preparation. Anesth Analg 1988; 67: 240-6. 